Authors: Sławomir Spadło, Damian Bańkowski, Piotr Młynarczyk

Title of article: „Badania wpływu obróbki wibrościernej na warstwy nanoszone techniką ESD” (“Research on the impact of vibratory machining on the layer applied with the ESD technique")

Mechanik, Vol. 91, No. 11 (2018): pages 1029-1031

DOI: https://doi.org/10.17814/mechanik.2018.11.184

\title{
Research on the impact of vibratory machining on the layer applied with the ESD technique
}

\author{
Badania wpływu obróbki wibrościernej \\ na warstwy nanoszone techniką ESD
}

\section{SŁAWOMIR SPADŁO DAMIAN BAŃKOWSKI PIOTR MŁYNARCZYK *}

The article presents the proposal of using abrasive treatment in vibrating containers for surface treatment applied with the Electro Spark Deposition technique. In tests on a carbon steel the layer was applied with a tungsten electrode. After the tungsten layers were applied, a vibro-abrasive treatment was carried out. Changes in the geometrical structure of the surface of the deposited layers before and after vibratory processing were investigated. In addition, the chemical composition and the thickness of the coatings were examined.

KEYWORDS: vibratory machining, surface smoothing, layer application, ESD, microstructure

The methods of improving the exploatability and regeneration of machine parts are gaining importance nowadays. The legitimacy of the recovery processes of the functional properties of machine parts depends mostly on the efficiency of the regeneration processes. In many cases, the cost of regeneration of machine parts after wear or failures varies from a few percent of the value of the part being repaired.

In the design processes of structural elements, the issue of reuse of consumable elements takes on a significant role, and many structures are designed in a way that will facilitate their regeneration in the future.

Methods of regeneration and surface modification are many, depending on the expected properties of the coatings and conditions of use as well as the coating materials used $[2,3,7]$. Thermal spraying and surfacing methods as well as friction methods are successfully used.

Electro spark deposition (ESD) uses short current pulses to deposit material from a working electrode onto a work surface to improve the properties of the surface layer, such as resistance to corrosion or scratches or hardness.

The method of electro-discharge coating is associated with the transport of energy and mass under conditions of electric discharge between the working electrode and the workpiece. The working electrode is an anode and the workpiece is a cathode $[2,8,10]$. The treatment takes place in a gas atmosphere, usually air. Inert gases are used to protect the applied layer from oxidation to form a protective atmosphere. The treatment can also take place in liquid media, e.g. in kerosene, oil.

\footnotetext{
* Dr hab. inż. Sławomir Spadło prof. PŚk (sspadlo@tu.kielce.pl), mgr inż. Damian Bańkowski (dbankowski@tu.kielce.pl), mgr inż. Piotr Młynarczyk (piotrm@tu.kielce.pl) - Katedra Metaloznawstwa i Technologii Materiałowych Politechniki Świętokrzyskiej
}

Classic curing using spark discharges allows the production of a modified layer with a thickness of a few to approx. $200 \mu \mathrm{m}$ on a limited surface (depending on the dimensions of the electrode). In most cases, WW modification using electric discharges is associated with increased roughness.

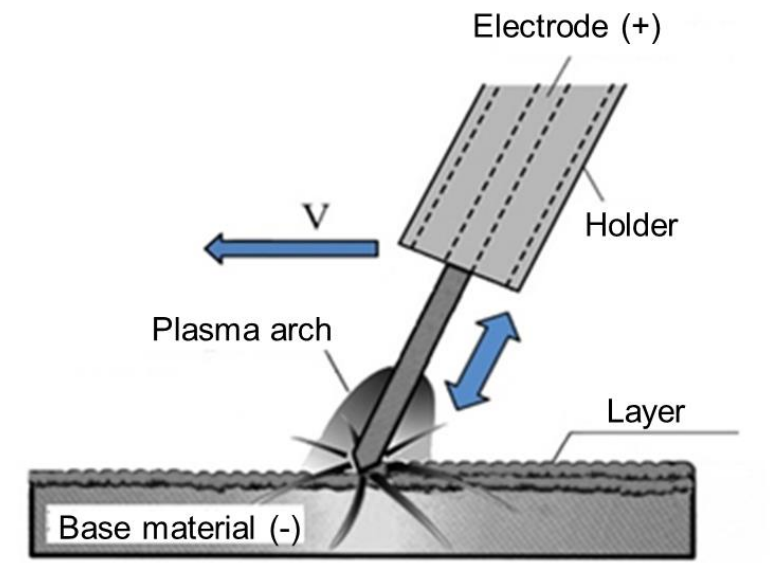

Fig. 1. Diagram of tungsten layer deposition using the ESD method

\section{Characteristics of vibro-abrasive machining}

Vibro-abrasive machining is a variation of container processing involving the use of energy of a vibrating work tank by putting in motion the work load [1, 4]. The working materials are most often abrasive shapes, support fluids, abrasive pastes and the workpieces themselves. Trajectories of labor components are the result of overlapping rotational motion around the drive axis of the device and rising and falling motion, colloquially referred to as the spiral motion [6,9]. Interactions between the elements of the charge cause microcracking of the surface of the workpieces and, as a result, abrasion of the surface. 
Container processing is used for surface finishing and is aimed at reducing its roughness, removing paint coatings, etc., traces of corrosion, heat influence or rounding of the edges or removal of burrs [11]. In addition, loose abrasive treatment can be used to achieve the effect of brightening, so-called mirror effect.

With the use of vibro-abrasive machining, the selection of process conditions/parameters is associated, such as:

- abrasive media (grinding and/or polishing),

- supporting liquids and/or machining pastes,

- processing time,

- operating frequency of the device,

- proportion of media and workpieces.

Processing time varies from a dozen or so minutes (silver jewelry in an inertial tank) to a few weeks (precious stones in drum or vibratory trowels) and depends on the method used, the abrasive and the workpieces.

The process can be carried out under the conditions:

- dry - using abrasive pastes and a suitable carrier (ground corncob or walnut shell),

- wet - usually with the addition of a booster fluid or an aqueous abrasive slurry - using resin or ceramic abrasive bodies or shots of stainless steel, acid-proof steel or glass.

\section{Subject of study}

The subject of the research were tungsten coatings made by ESD method on a C45 steel substrate, as a result of electric discharges controlled by means of a generator constructed specially for this purpose.

ESD process parameters:

- voltage $U=600 \mathrm{~V}$,

- capacity of capacitor $C=50 ; 150 ; 250 \mu \mathrm{F}$,

- frequency $f=50 \mathrm{~Hz}$.

After applying tungsten coatings, the objects were subjected to vibro-abrasive treatment.

The Rollwasch SMR D 25 device was used for the tests. PB 14 KT polyester fittings and ca. $150 \mathrm{ml} \mathrm{FE-L120-B32/R}$ support fluid were used as the working load to create conditions conducive to polishing and passivation of the surface. The vibration frequency of the working tank was set at $2500 \mathrm{~Hz}$, while the treatment times were 60,120 and 180 min respectively.

\section{Results}

The geometric structure of obtained surfaces on the Taylor Hobson Talysurf CCl Lite optical profilometer was measured [5]. The results of measurements of changes in the geometric structure of the surface are given in the table. The measurements were carried out immediately after the ESD treatment, followed by subsequent vibro-abrasive machining at appropriate intervals: $60,120,180 \mathrm{~min}$.

TABLE. Results of measuring changes in the geometric structure of the surface

\begin{tabular}{|c|r|c|c|}
\hline $\begin{array}{c}\text { Capacitor capacity } \\
\mu \mathrm{F}\end{array}$ & $\begin{array}{c}\text { Machining time } \\
\mathrm{min}\end{array}$ & $\begin{array}{c}\mathrm{Sa} \\
\mu \mathrm{m}\end{array}$ & $\begin{array}{c}\mathrm{S} z \\
\mu \mathrm{m}\end{array}$ \\
\hline \multirow{4}{*}{50} & 0 & 9,598 & 112,093 \\
\cline { 2 - 4 } & 60 & 5,895 & 65,754 \\
\cline { 2 - 4 } & 120 & 5,578 & 51,880 \\
\cline { 2 - 4 } & 180 & 4,931 & 39,883 \\
\hline \multirow{4}{*}{150} & 0 & 7,495 & 63,407 \\
\cline { 2 - 4 } & 60 & 6,138 & 37,880 \\
\cline { 2 - 4 } & 120 & 5,650 & 35,973 \\
\cline { 2 - 4 } & 180 & 4,443 & 32,742 \\
\hline \multirow{4}{*}{250} & 0 & 4,206 & 53,156 \\
\cline { 2 - 4 } & 60 & 3,530 & 35,911 \\
\cline { 2 - 4 } & 120 & 3,201 & 26,050 \\
\cline { 2 - 4 } & 180 & 2,945 & 21,535 \\
\hline
\end{tabular}

On the basis of 3D measurements of the geometric structure of the tungsten layers applied, it can be concluded that the smallest capacitance of the capacitors used has surfaces characterized by higher values of the highest elevation parameter of profile $R_{\mathrm{p}}$, with a higher number of peaks with significant heights than those obtained with the largest capacitors capacity. The highest surface roughness was twice as large $S z=112 \mu \mathrm{m}$ for capacitors with a capacity of $50 \mu \mathrm{F}$ than when using capacitors with a capacity of $250 \mu \mathrm{F}: S z=53 \mu \mathrm{m}$.

Exemplary geometric structures of the surface are shown in fig. 2 and fig. 3.

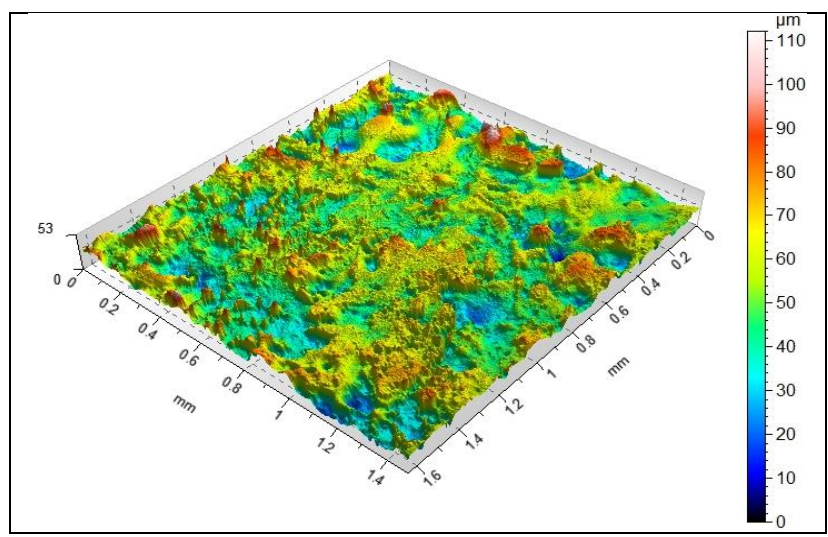

Fig. 2. 3D structure of the surface after application of the tungsten layer $(C=50 \mu \mathrm{F})$

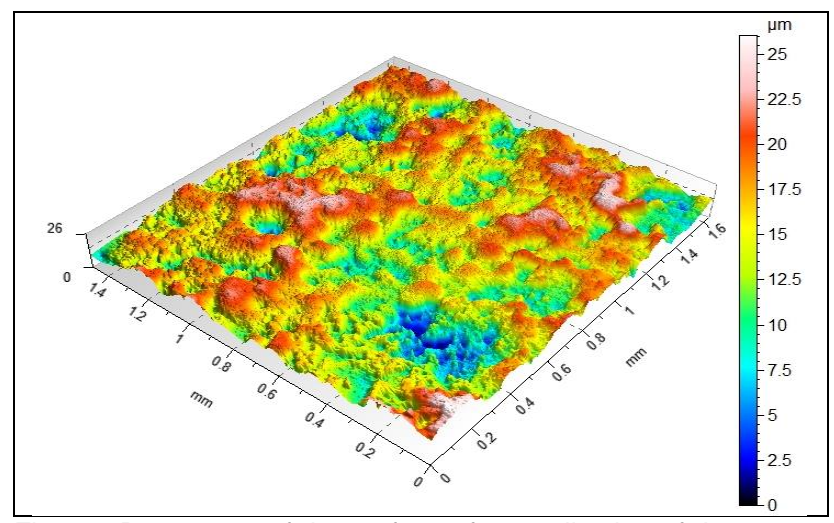

Fig. 3. 3D structure of the surface after application of the tungsten layer $(C=250 \mu \mathrm{F})$ and after vibro-abrasive treatment $120 \mathrm{~min}$

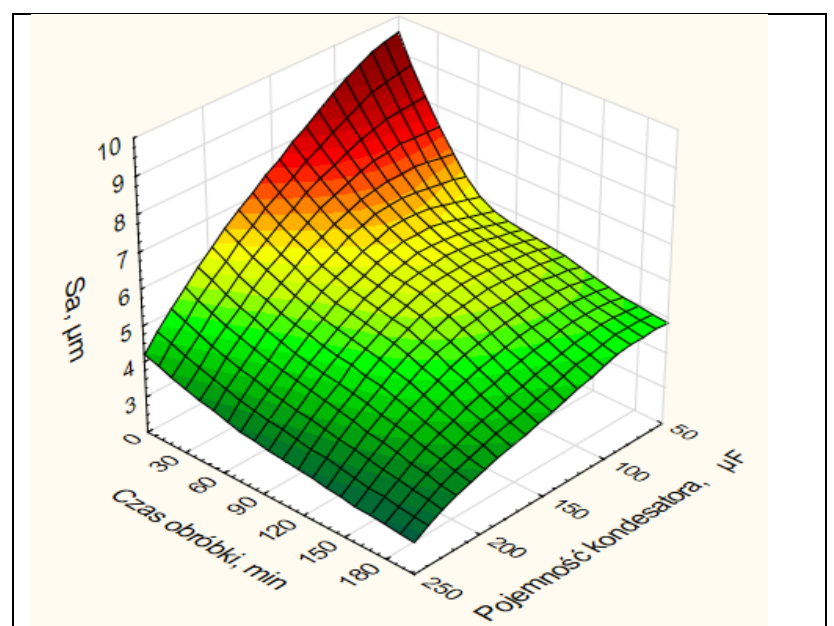

Fig. 4. Dependence of changes in the arithmetic mean surface roughness $S a$ from the time of vibro-abrasive machining and the capacity of the capacitor 
The results of the measurements made it possible to construct in the Statistica program graphs of the arithmetic mean of the surface roughness (fig. 4) and the maximum surface height $S z$ (fig. 5) from the time of processing and capacitance of the capacitors used to apply the coatings.

It should be emphasized that the surface roughness parameter $S z$ decreases the fastest in the first machining period - for the first 60 minutes. This result confirms that in the abrasive treatment the most intense interactions between the workpieces and abrasive shapes occur on the elevations of the roughness profile. If $50 \mu \mathrm{F}$ capacitors are used in the power supply system, a reduction from $112 \mu \mathrm{m}$ to $65 \mu \mathrm{m}$ is made.

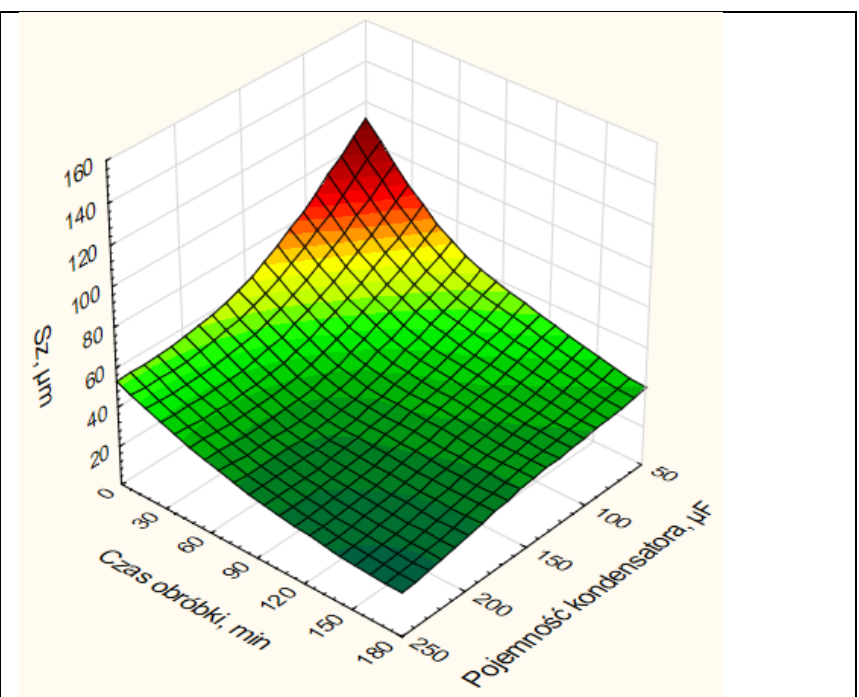

Fig. 5. Dependence of the changes in the highest surface roughness $S z$ from the time of vibro-abrasive machining and the capacity of the capacitor

This example confirms the thesis that the innermost tops of inequalities are first removed. Extending the machining time further reduces the analyzed SGP parameters, but the process stabilizes.

Examination of the surface layer was supplemented with a linear and point analysis of the chemical composition of the applied layer. They were carried along the selected line on the transverse sample wipe, so as to cover the native material and the modified layer.

Distributions of selected elements (fig. 6) were obtained in the area of the connection of the layer applied to the substrate. The analysis was carried out using an OXFORDX-MAX electron microprobe.

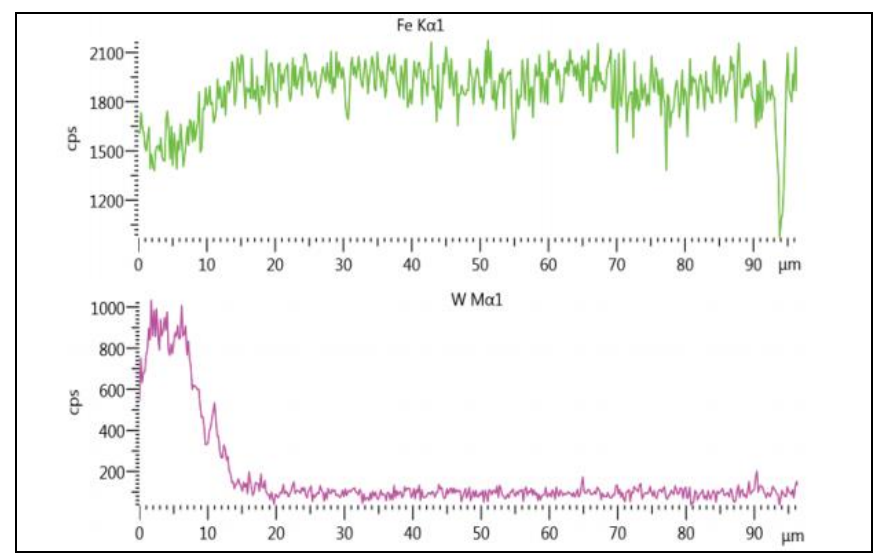

Fig. 6. SEM photograph and line analysis of the chemical composition of the deposited layer with a capacitance of $50 \mu \mathrm{F}$ capacitors

\section{Conclusions}

Investigations of the electrolytic shielding process using a tungsten electrode showed that:

- capacity of the capacitors has a significant influence on the geometric structure of the surface. The use of capacitors with a smaller capacity caused a greater distortion of the structure and the formation of a structure with a large number of sharp vertices,

- due to the use of larger capacitance capacitors, the surface layer was more flat and consisted mainly of pure tungsten, while with smaller capacitances, a diffusion layer of approx. $50 \div 60 \%$ tungsten was observed,

- thickness of the embedded layer varies depending on the capacity of the capacitors: from $10 \mu \mathrm{m}$ (at low capacity) to $30 \mu \mathrm{m}$ (at high capacity),

- machining with loose abrasive profiles - vibro-abrasive allows to reduce the arithmetic mean of the surface roughness of the deposited tungsten layers, so it can be successfully used for finishing hard tungsten layers,

- the largest reduction in the largest roughness of the $S z$ surface takes place in the first machining period - for the first 60 minutes.

\section{REFERENCES}

1. Bańkowski, D. Spadło, S. "Influence of the smoothing conditions in vibro-abrasive for technically dry friction the parts made of steel X160CRMOV121". Proc. 25th Int. Conf. Metall. Mater. Metal. (2016): pp.: 1019--1024.

2. Davydov A.D., Kozak J. "Physico-chemical principles of electrochemical discharge machining". Surface Engineering and Applied Electrochemistry. 3 (1991): pp. 3-13.

3. Depczyński W. "The selected properties of fusion of fe foam and sheet metal with use of sintering in dissociated ammonia". Proceedings of 25th International Conference on Metallurgy and Materials. METAL. (2016): pp. 682-687.

4. Filipowski R., Marcinak M. „Obróbki powierzchniowe i erozyjne". Warszawa: Oficyna Wydawnicza Politechniki Warszawskiej (2000): pp. 304-308.

5. Janecki D., Stepien K., Adamczak S. "Problems of measurement of barrel- and saddle-shaped elements using the radial method". 19th IMEKO World Congress Location. 43, 5 (2010): pp.: 659-663.

6. Kacalak W., Lipiński D., Bałasz B., Rypina Ł., Tandecka K., Szafraniec F. "Performance evaluation of the grinding wheel with aggregates of grains in grinding of Ti-6Al-4V titanium alloy" Int. J Adv Manuf. Technol. (2018): pp. 94: 301. doi.org/10.1007/s00170-017-0905-x.

7. Schumacher B. "After 60 years of EDM the discharge process remains still disputed". Proc. XIV. ISEM. Edinburgh, UK. 149, (2004): pp. 376-381.

8. Spadło S., Młynarczyk P., Łakomiec K. "Influence of the of electrical discharge alloying methods on the surface quality of carbon steel". The International Journal of Advanced Manufacturing Technology. 89, 5-8, pp. 1529-1534. DOI 10.1007/s00170-016-9168-1.

9. Starosta R. "Surface Treatment". Gdynia: Wydawnictwo Akademii Morskiej w Gdyni, 2008.

10. Świercz R., Oniszczuk-Świercz D. "Experimental investigation of surface layer properties of high thermal conductivity tool steel after electrical discharge machining". METALS. 7, 12, Article No.: 550, Published: DEC 2017.

11. Woźniak K. "Obróbka powierzchni w wygładzarkach pojemnikowych". Warszawa: WNT, 2017.

Translation of scientific articles, their computer composition and publishing them on the website www.mechanik.media.pl by original articles in Polish is a task financed from the funds of the Ministry of Science and Higher Education designated for dissemination of science. 